\title{
Sino-Danish cooperation in the energy transition
}

Birte Holst Jørgensen' and Stine Haakonsson²

'Department of Wind Energy, Technical University of Denmark; ${ }^{2}$ Department of Organisation, Copenhagen Business School

\section{Introduction}

The sustainable energy transition is a critical shift to secure the future of the planet and the existence of human beings. Both sustaining current living standards of the global middle class and improving the lives of people still living in poverty are at stake. The transformation of our energy systems towards a sustainable, more efficient and affordable model encompasses energy production, transmission and consumption. The impact of institutional drivers and barriers, and who uses energy and at what cost, are also key factors. Moreover, this transformation comprises different scales, from the household to national policy, and from international markets and technology transfer networks to international governance of energy and climate.

The global political agenda on climate change is driving this unprecedented transformation of energy systems, facilitated by a rapidly evolving techno-economic system, changing customer demands and new business opportunities. Innovation and large-scale adoption of clean energy technologies, which complement other emission-based policies, are key to decarbonising the energy sector and combatting climate change (WEF 2020; IRENA 2020). While policy innovation and implementation often takes place locally and nationally, international cooperation is critical given the urgency of energy and climate challenges (Gluckman et al. 2017). In September 2020, Xi Jinping, the Chinese President, announced China's objective to achieve a carbon neutral energy system by 2060, with a carbon emissions peak in 2030. Alongside this target, $X_{i}$ Jinping made an appeal for international collaboration, "We call on all countries to pursue innovative, coordinated, green and open development for all, seize the historic opportunities presented by the new round of scientific and technological revolution and industrial transformation, achieve a green recovery of the world economy in the post-COVID era and thus create a powerful force driving sustainable development" (Speech at UN General Assembly, 22 September, 2020). Meanwhile, in Denmark, the stated political objective is to reduce carbon emissions by $70 \%$ by 2030 .

Cooperation on sustainable energy has increasingly traversed geographies. Though at different scales and following slightly different paths, China and Denmark are among countries with ambitious goals for a sustainable energy transition. Denmark has long been a forerunner in sustainable energy transition, while China is currently leading the world in investments. At the beginning of the century the two countries established energy-related cooperation and the transfer of knowledge, practice and technologies (see below). Today, this collaboration goes beyond the governmental and diplomatic sphere with the market nurturing innovative systems from both countries for developing new energy solutions (Haakonsson \& Slepniov 2018; Haakonsson et al. 2020).

In this chapter, we examine the rationales for international energy-related cooperation in general, and for Sino-Danish cooperation in particular. We explore the development of the strategic partnership between the countries, and the visions and driving forces related to sustainable energy technologies. We scrutinize the complex network of collaborative R\&D efforts between Denmark and China and put this in the context of international energy technology cooperation.

\section{International energy R\&D cooperation}

The transition towards a sustainable, affordable and reliable energy system will require nothing short of a revolution in energy technology. It necessitates a radical change in how we organize our societies, encompassing infrastructure, institutions and markets along with technological improvements. Existing technologies need to improve and be deployed in a more astute way, particularly in energy efficiency, alongside the introduction of radically new technologies and concepts. The scale of the energy challenge and the heterogeneity and complexity of energy systems demands a broad offering of new energy technologies, and an acceptance that some may not succeed. Technology leaders should adopt a push and pull strategy to accelerate the development cycle from research to market deployment. Finally, while economic development is dependent on reliable and affordable energy systems, huge opportunities exist for technology providers on the global market. Meanwhile, new concepts such as the 'post-growth society' are emerging, and will engender changes in mobility, interconnectivity, smart cities, the sharing economy and bottom-up initiatives in sustainable development.

The question is not whether to engage in international cooperation on energy transition, but to what degree, 
where and how. A good starting point are initiatives directly linked to industry innovation through research and development (R\&D). Although international energy RED cooperation has been high on the political agenda in times of energy crisis and other global challenges, it seldom goes beyond knowledge exchange and memorandums of understanding (Edler 2010; Gray et al. 1985). National technological capacities tend to be associated with international competitiveness, technological potency and consequent negotiating strength (Gray et al. 1985; Grin et al. 2010; Mazzucato 2015; Geels and Schott 2007). Balancing government strategies for competitiveness and transition with firm ambitions for scaling up in international markets is challenging. Different political systems may have conflicting objectives, making international cooperation even more difficult (Mitchell 2010) and shaping governments' innovation and energy policies, an area high on the agenda in terms of national security.

\section{Benefits of international R\&D cooperation}

International RED cooperation brings a number of benefits (Gray et al.1985; Georghiou 1998; Boekholt et al. 2009; Archibughi et al. 1999; Kuemmerle 1999) that can be grouped into two major categories. Narrow or direct benefits for science and research activities undertaken by the science community aim to stimulate cross-fertilisation, enlarge the scale and scope of research activities, improve the capabilities of researchers and institutions, harvest synergy effects and complementarity, set the standards of future technologies, secure access to state-of-the-art knowledge and attract resources for science, technology and innovation. Taken together, these contribute to scientific and knowledge competences and competitiveness, as well as industry level dynamic capabilities and absorptive capacity. Broader or indirect benefits for other political and economic objectives provide the means for addressing global challenges, such as climate change, while seeking to improve national competitiveness, foreign relations and development policies. Often, trade-offs have to be made between conflicting policy goals, not least in energy policy.

Narrow/direct benefits of international cooperation The direct, scientific benefit of international cooperation mainly relates to the potential to improve scientific quality, scope and critical mass by connecting resources and knowledge across national borders. The concept is embedded in the scientific norms of communalism, universalism, disinterestedness and organised skepticism (CUDOS). Scientists build on merit review, critical thinking, diversity of thought, and transparency and knowledge exchange with peers. It is a mutual exchange, though not simultaneously and not necessarily with the same peers. The benefit is both to secure access and attract state-of-the-art resources and knowledge (Boekholt et al. 2009).

Access to expertise, knowledge or skills aims to enhance scientific or technological excellence, reaching across national boundaries. This is clearly the case for a small country such as Denmark where competences may be under the threshold for critical mass and/or limited to specific areas. It is also the case for a large country such as China that seeks to improve its leadership in science and technology. China's rise on the global stage is also reflected in the fields of research and higher education. Since the late 1980s, China has sent tens of thousands of young scientists and engineers on research stays in leading universities abroad, but while many in the past chose to remain abroad, there has been a concerted effort by the Chinese government in recent years to encourage them to return home (Basu et al. 2018). Today China has the second largest R\&D budget in the world after the USA, the second largest pool of researchers after the EU and has surpassed the USA in numbers of scientific publications (d'Hoodge et al. 2018). Recent scholarly work also highlights the potential of internationally organized and dispersed innovation. Indeed, the current stage of globalization involves new forms of global organized innovation networks (Ernst 2002; Barnard and Chaminade 2017; Gu et al. 2016).

Access to unique sites and specialized facilities is a further benefit of cooperation. A good example is how Danish researchers working on energy-related fusion technology have, under the auspices of the Sino-Danish Center for Education and Research, established a longterm cooperation with researchers from the Chinese Academy of Sciences' Institute of Plasma Physics (IPP). This provides them with access to the Experimental Advanced Superconducting Tokamak, EAST, an experimental superconducting tokamak magnetic fusion energy reactor in Hefei. Such partnerships mean the costs and risks of expensive research infrastructure are shared; examples are the CERN in Switzerland, the ITER tokamak facility in Southern France and the European Spallation Source (ESS) in Southern Sweden. Research and development that necessitates large-scale science infrastructure is increasingly organised into global networks. The Huairou Science City Park, which is under construction just north of Beijing, is a good example.

\section{Indirect/broad benefits of international cooperation} In addition to the direct benefits of international cooperation, indirect benefits are associated with broader economic, political and cultural objectives. Competitiveness is becoming a very important driver at both national and supranational/regional levels. The EU aims to use international cooperation in research and innovation to not only improve excellence in this area, but to strengthen economic and industrial competitiveness - outward strategies provide access to new markets while inward strategies attract businesses and resources to individual countries. Meanwhile, Chinese innovation policy has shifted along similar lines over the past decades, moving from leveraging indigenous innovation to exploring international collaboration and strategic alliances (d'Hoodge et al. 2018; Fu and Mu 2014). 
Opening up to new markets is particularly promising for companies in the renewable energy industry. Opportunities for new energy technologies are booming in emerging markets where economic growth relies on a secure, affordable and sustainable energy system.

RED cooperation also benefits exports as it may contribute to opening up to and providing access to important actors in the energy sector, such as governmental institutions in charge of implementing, operating and maintaining infrastructure and sustainable investments. Global competition among technology providers is fierce and irrespective of national barriers, energy costs define whether an investment is remunerated in the longer term. Over the last decade, there has been a market tendency towards auction systems for renewable energy infrastructure. Energy technology systems are complex and comprise a wide variety of knowledge-intensive technologies and standard components, all of which rely on a process of smooth integration into the local energy system.

Attracting knowledge and inward investment is another driver of international cooperation. In a Research and Innovation (REI) assessment of Denmark, enhanced international cooperation is highlighted as a mechanism to increase the relatively low number of new doctoral students and the quality and availability of research and innovation skills (Knudsen et al. 2018). Indeed, the work of innovation centres in global technology hotspots facilitates cooperation and attracts universities and companies. These centres are often aligned with the Invest in Denmark programme that aims to attract foreign direct investments (FDI), including R\&D-intensive companies that wish to link up with key players in Denmark, in areas such as renewable energy. Today, most countries have scientific officers within their diplomatic teams to facilitate and nurture international science collaboration.

The magnitude of addressing global energy and climate challenges is perhaps the single most important driver in international energy technology cooperation and therefore is helpful in seeking to understand the dynamics of international collaboration in general. The climate challenge is simply too great to be tackled by one country alone, and the involvement of countries with different RED knowledge bases and financial resources is essential to secure successful outcomes (Boekholt 2009). This cooperation is evident in all phases of the value chain from basic research to deployment of known technologies that have to be adapted to local systems and contexts.

Barriers in international energy technology cooperation While international cooperation is expected to bring about direct economic, societal and technological benefits, there are barriers that need to be addressed. Access to promising new energy technology and systems markets does not mean that market share is evenly distributed (Georghiou 1998). Emerging markets such as China do not open up their markets to foreign products and direct investment without implementing measures to protect the competitiveness and development of their domestic industry and knowledge base. Since 2006, China has implemented industrial innovation policies that favour indigenous technologies at the expense of imported technologies. These policies include a mandate to replace imported technology in core infrastructure, the use of public procurement to block products not designed, developed or produced in China, a requirement for imports to pass product testing and approval regimes, the use of domestic patent rules, and the leveraging of Chinese industrial and technology standards as market barriers to foreign technology. Consequently, many Chinese firms have developed to a size and standard that is fast closing the gap on foreign technology (Fu 2015; Lema et al. 2020), presenting a huge challenge to incumbent companies from the so-called advanced economies.

Another barrier is the rise in institutional complexity that results from collaboration, termed in the business literature as the 'liability of foreignness'. Different cultures, national innovation systems, structures and priorities make it difficult to successfully match research communities and identify the relevant funding agencies, as well as to agree on appropriate administrative and monitoring mechanisms for project development. National systems follow procedures and rules developed over time to support their respective research communities. Often, restrictions exist for foreign access to national programmes, making it more difficult to align administrative regimes. Further, development expenditure is often considered as an investment, and therefore not adequately compensated. In addition to formal institutional differences, less visible differences around traditions, work practices and culture make establishing close collaboration a long-term investment - at both the individual and the institutional level.

From a narrow national funding agency perspective, management of international cooperation is cumbersome, time-consuming and is obliged to demonstrate a reasonable return on investment. Public R\&D expenditure is seldom a governmental priority in times when populations expect tangible and short-term economic and welfare benefits. This makes it even more difficult to spend RED resources on international research cooperation instead of national research projects (Stamm et al. 2012).

Even though the World Trade Organization (WTO) introduced a binding agreement on intellectual property rights (IPR) (TRIPS Agreement), or patent protection, the perception persists that international cooperation faces serious challenges. The purpose of IPR is twofold, to foster the development of new technologies while facilitating their diffusion across and within countries. It aims to boost the private economic incentive to invest in innovation, and promote the creation and transfer of technology. Conversely, IPR also holds back the development and diffusion of new technologies as it 
Mission Innovation(MI) is a global initiative of member countries from five continents, 24 countries and the EU, working to accelerate clean energy innovation.

China and Denmark were among the founding countries of Ml. When world leaders came together in Paris in December 2015 to undertake ambitious efforts to combat climate change, a group of countries launched Ml to dramatically accelerate global clean energy innovations with the objective of making clean energy widely affordable.

As part of the initiative, participating countries committed themselves to doubling their governments' clean energy research and development investments over five years, while encouraging greater levels of private sector investment in transformative clean energy technologies.
Ml complemented another global initiative, Clean Energy Ministerial (CEM), established in 2009 and focused on deployment measures for a global clean energy economy

China and Denmark hosted ministerial meetings of CEM and MI, in Beijing in 2017 and in the Oresund Region in 2018, respectively.

Member countries cooperate on a number of innovation challenges of common interest.

Danish and Chinese researchers also engaged with Sino-Danish Center (SDC) to cooperate closely on Smart Grid innovation challenges, which China coleads together with Italy.

http://mission-innovation.net increases costs and has the potential to limit availability. The literature on IPR reveals its systematic impact on technology transfer and licensing for middle-income countries (emerging economies), for which the risk of imitation in the absence of IPR is relatively high. Though concerns exist around the lack of enforcement of IPR in emerging countries, recent empirical analysis has found that IPR is not a barrier to the diffusion of energy technologies, and that theft of intellectual property in new energy technologies is exaggerated. Indeed, IPR should be seen as an important administrative aspect of international cooperation that needs to be addressed early (Anadon et al. 2015).

Finally, international cooperation is vulnerable to changes in financial and political commitment. It can be exposed to partner withdrawals and cutbacks in funding, as countries tend to change strategy over time, at times opening up, at other times closing in. This has clearly been demonstrated by the Trump administration that has downsized or cancelled financial and political engagement in international R\&D cooperation. Both its engagement in Mission Innovation and the US-China energy collaboration have been impacted. The development of institutionalized country-level partnerships has become a critical tool in sustaining collaboration, inspiration and co-creation, particularly for smaller countries.

1 www.energy.gov/ia/initiatives/us-china-clean-energy-research-center-cerc
In conclusion, international cooperation has the potential to increase the scope and scale of research and can therefore develop solutions more effectively and efficiently to crucial challenges and problems particularly those related to the transition of energy systems. International R\&D cooperation is also characterized by differing and overlapping policy objectives, ranging from national competitiveness to trade, foreign investment, development aid and science diplomacy, together comprising a comprehensive package of external action (EU Commission 2012). While some barriers can be overcome by drafting careful agreements, others are related to transaction costs and should be resolved through organizational and procedural measures. An example follows of a broad international RED cooperation, involving China and Denmark

\section{Sino-Danish energy cooperation}

Sino-Danish cooperation is founded on long-term diplomatic relations. Denmark is the only country to have an unbroken diplomatic presence in China since 1908. On $11^{\text {th }}$ May 1950, Denmark and China consolidated their relationship by establishing embassies and ever since Danish recognition of the Peoples Republic of China and its national territory (the One-China policy) has remained unchanged. China's increasing integration into the international community has led to dialogue and cooperation across all areas of common interest. 
In 2008, the two governments signed an agreement to establish a Strategic Partnership in areas of common interest. Most importantly, the intention was to strengthen political dialogue between the two governments to foster cooperation in areas such as climate, energy, environment, research, innovation and education. In 2017, this cooperation was upgraded through the China-Denmark Joint Work Programme 2017-2020

Government-to-government initiatives in the energy area included the Wind Energy Programme (WED), 2007-2010, which targeted capacity building in wind energy to contribute to China's energy supply. The Renewable Energy Programme (RED), aimed at enhancing capacity for renewable energy development in China, ran from 2009-2013. A key component was the establishment of China's National Renewable Energy Centre to support the Chinese government and society in promoting renewable energy development. This led to the founding of the China Renewable Energy Center (CNREC), which today is a leading Chinese government think tank for renewable energy policy. Government-to-government energy cooperation has further been strengthened by a number of Memorandums of Understanding (see box below for details) that seek to enhance Sino-Danish cooperation between companies, organizations and institutions, and thereby facilitate Danish stakeholders' entry into the Chinese energy market and vice versa.

\section{Overview of Memorandums of Understanding between the Danish Ministry of Climate, Energy and Utilities and Chinese energy authorities}

1. National Energy Administration (NEA)Underlines and supports cooperation with CNREC, 2012-

2. Ministry of Housing and Urban-Rural Development (MoHURD)

Cooperation on energy efficiency in buildings, 2014

3. National Energy Conservation Cooperation on energy efficiency, 2014-

4. Ministry of Science and Technology (MOST) Cooperation on development and demonstration projects, 2012-

5. National Development and Reform Commission (NDRC), 2013-

Promotes a mutually beneficial partnership between Denmark and China in the field of climate and energy planning, and promotes the transition to low carbon economies
Sino-Danish scientific and research cooperation is deeply embedded at multiple levels and embraces individual researchers, universities and research council systems. Researchers - often supported by grants and support mechanisms - cooperate with peers across universities from the two countries. Universities build international alliances with partner universities on research and education. For example, Copenhagen University is a member of the International Alliance of Research Universities (UERU) together with Peking University and nine other international universities. Until recently, Copenhagen University also had a close partnership with Fudan, one of the world's leading universities. The research council systems in both countries have made joint calls for proposals and supported research projects. For example, the National Science Foundation of China (NSFC) and the Danish National Research Foundation have supported three Centres of Excellence in the energy sector, focusing on solar, materials and fuel cells.

Following the launch of the Danish Strategic Action Plan, existing mechanisms to facilitate and strengthen researcher mobility and institutional collaboration were further complemented by new initiatives to overcome barriers and generate direct and indirect benefits. These included joint research and innovation proposals by MOST and Innovation Fund Denmark, the Danish International Network Programme. The Danish strategy for science cooperation is described below.

\section{Danish strategy for Sino-Danish science cooperation}

The Danish strategy for science cooperation between China and Denmark highlights the enormous value of Sino-Danish research and higher education cooperation to the Danish society and its position in the global knowledge economy.

It has three aims:

- facilitating access to Chinese partners

- attracting Chinese talent to Danish stakeholders in China and Denmark

- improving Danish researcher and student access to, and insight into, Chinese educational systems and RGD environments

The strategy outlines 11 actions for strengthening research and higher education cooperation with China and also contributes to the Danish government's China Strategic Action Plan. The establishment of the Sino-Danish Center for Education and Research was highly prioritized in the strategy.

Source: Strategi. Vidensamarbejde mellem Danmark og Kina 2008 




Figure 1 Total collaborative co-publication article outputs over time.

With strong political support from both sides, the Sino-Danish Center (SDC) was established in 2010 and is a partnership between all eight Danish universities, the Chinese Academy of Sciences (CAS) and the University of Chinese Academy of Sciences (UCAS). The overall objective is to promote and strengthen collaboration between Danish and Chinese learning environments and increase the movement of students and researchers between the two countries. Activities include research collaboration within seven focus areas, including sustainable energy, affiliated Masters programmes and training of PhD students. In the field of energy technology there is a dedicated sustainable energy research area as well as a more generic social science area with a strong focus on renewable energy.

Research directly linked to energy technology includes a broad range of topics that have emerged over time as relevant for cooperation. Initially, the Sino-Danish research community focused primarily on the supply side of energy systems, including fusion, solar, wind, bioenergy (thermal and biological) and, over time, energy systems analysis. Following a number of researcher-practitioner seminars on technological solutions for system integration of renewables, a new targeted approach was agreed upon to address the challenges related to the development, integration, operation, management and optimization of accessible, reliable and resilient energy systems, with an increasing focus on renewable energy resources.

In addition to the technological and energy system projects, a considerable amount of Sino-Danish research collaboration focuses on societal impacts of energy transition. This involves company and industry level research on innovation, technology transfer and learning; collaboration on policy-related issues of transformative innovation, innovation policy and the socio-economic consequences of energy transition; macro initiatives related to the digital transformation, use of artificial intelligence and machine learning; and long term strategies such as the Belt and Road Initiative and the changing world order. New emerging projects integrate differing levels of analysis and disciplines, such as projects on sustainable smart cities and zero-energy houses, dispersed green technologies and end-user involvement.

\section{Sino-Danish R\&D output}

As part of this report, we conducted a bibliometric study to better understand the complex network of collaborative R\&D efforts between Denmark and China (Parraguez 2020). We analyzed the key characteristics of the evolving Sino-Danish collaborative research eco-system across multiple locations, organizations, topics and individuals. While the study furnishes information on Sino-Danish cooperation in general, its focus is technological projects related to the sustainable energy transition. Scientific co-publication provides some insights into research collaboration. Figure 1 reveals a general increase in collaboration. However, as this figure exclusively shows peer reviewed co-publications, this is not a measure of all Sino-Danish research collaboration since most of this is not necessarily co-published.

Figure 1 shows that co-publication dates from the 1970s and increases significantly from 2005 onwards, with consistent annual growth of around 20\%. Energy-related records numbered 1,850 or $15 \%$ of all publications. 


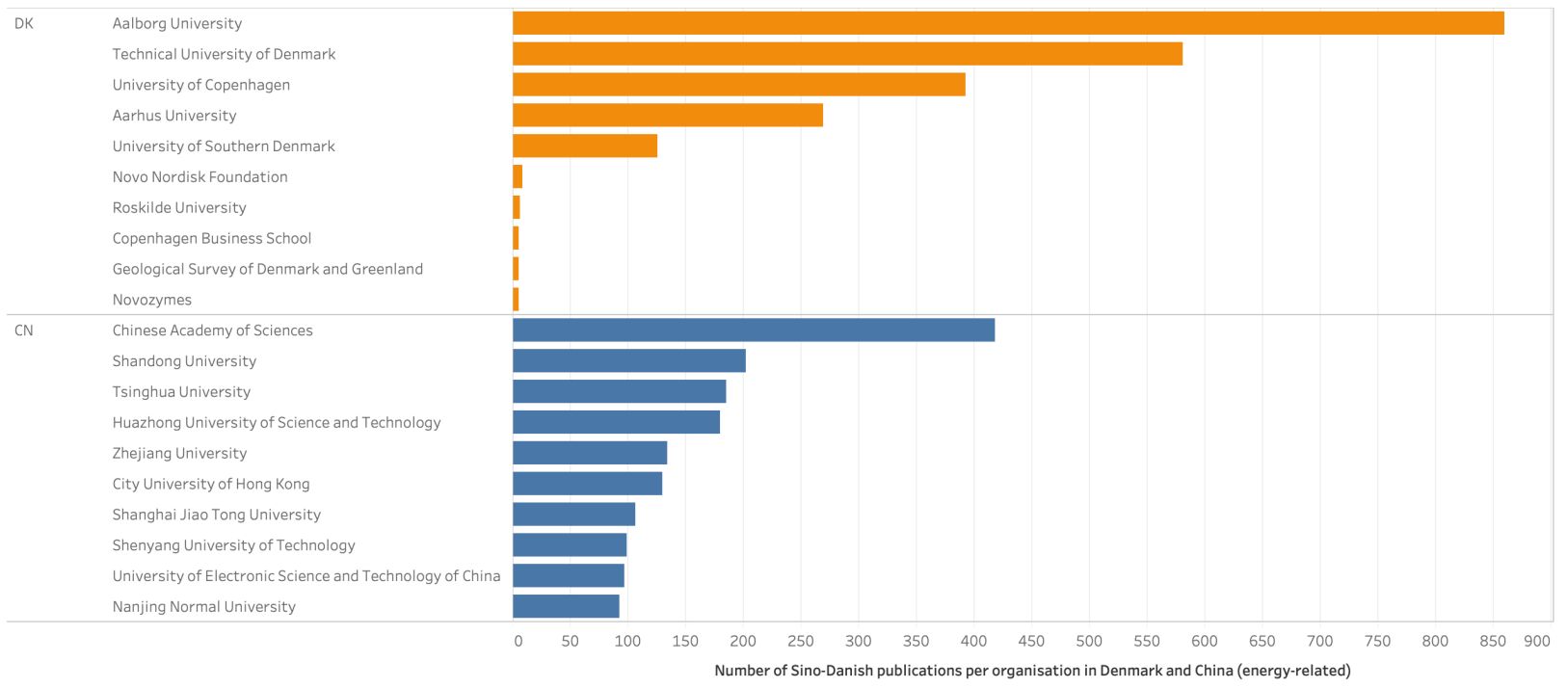

Figure 2 Top ten organisations in China and Denmark with scholars involved in energy-related scientific co-publication

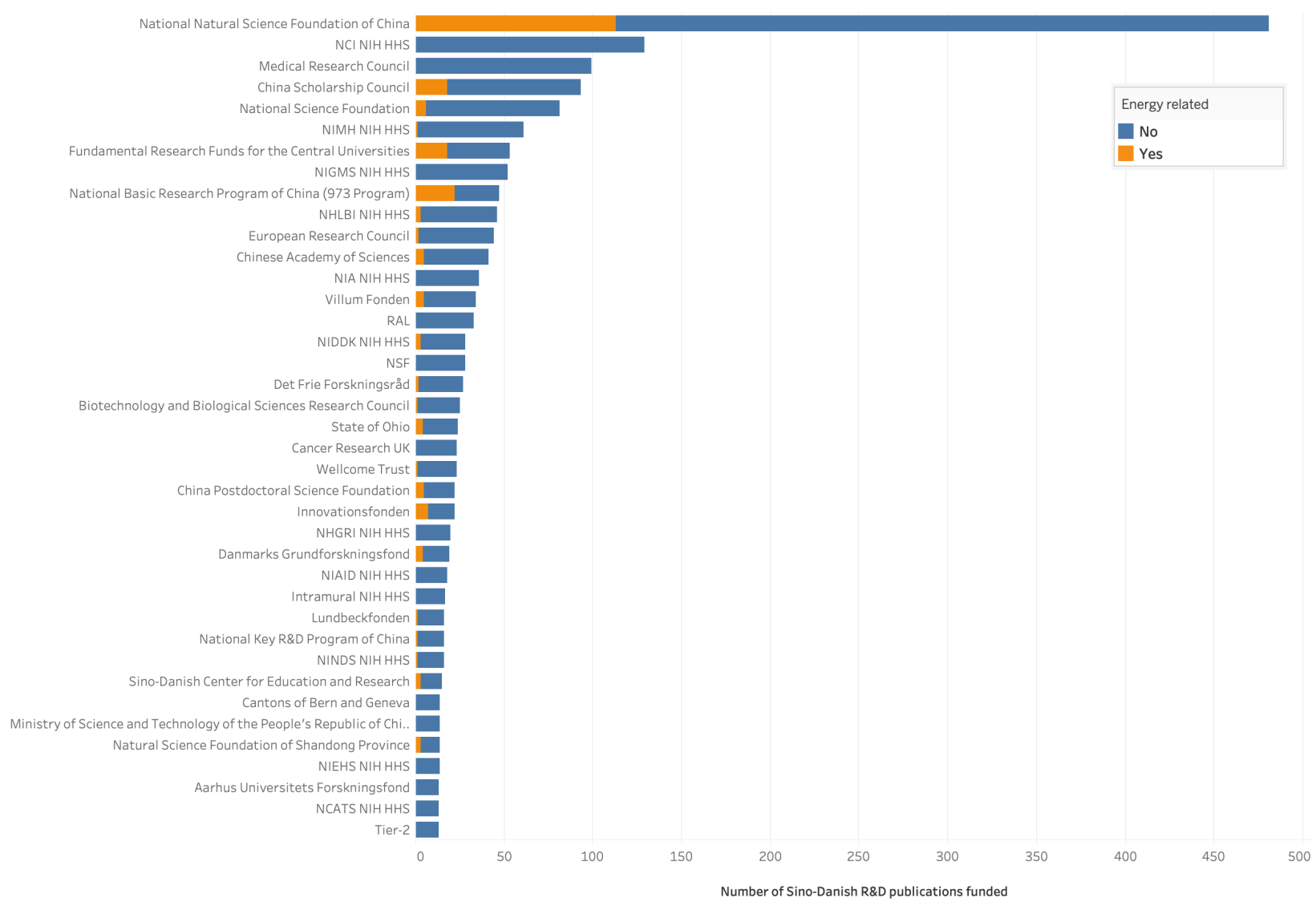

Figure 3 Funding sources mentioned in the acknowledgements sections of Sino-Danish co-publications 
The top five organizations involved in overall SinoDanish co-publication are, in order, the University of Copenhagen, the Chinese Academy of Sciences, Aarhus University, the Technical University of Denmark and Aalborg University. The same institutions comprise the top five within energy-related technology, but due to the strong engineering focus of energy research, the order differs: Aalborg University, the Technical University of Denmark, the Chinese Academy of Sciences, the University of Copenhagen and Aarhus University.

Chinese organizations are by far the largest source of funding. The National Natural Science Foundation of China is the top funding organisation, both for general and energy research. Likewise, the China Scholarship Council and the National Basic Research Programme of China (973 Programme) contribute financially to Sino-Danish collaboration. The Danish Villum Foundation is ranked at 14 in terms of funding, with only a small funding contribution to energy-related research, while the Innovation Fund Denmark is ranked at 24, producing - proportional to its size - a substantial volume of energy-related research.

Sino-Danish collaboration is not limited to bilateral relations but plays out globally, as illustrated in the networks of co-authors in Figure 4. Researchers co-publish internationally and seek out their peers at international conferences, during individual research stays or via university alliances and public support mechanisms, nurturing a broader scope of high quality networks. The leading country for both general and energy specific co-publication activities is the USA with 4352 and 431 records respectively. The United Kingdom ranks second with 2889/203 records, followed by Germany with 2377/148 records.

However, when analysing technical sciences broadly, China leads in Danish scientific co-publications, surpassing marginally Germany and the USA. Figure 5 contains data from 2014 to 2019 and shows co-au- thored publications in the technical sciences (engineering, environmental science, etc.) between Denmark and other countries (see https://deffopera.dk/).

The analysis identified four main clusters covering engineering+, materials, applied social and earth sciences, and human factors, the latter being much smaller. Each cluster was divided into sub-topics. The engineering factor in energy is clearly dominant, but chemistry and materials science are also significant. Economics stands out within applied social and earth sciences.

The complex connections between topics within energy are illustrated in Figure 6, showing the clusters and sub-groups of co-published papers where Sino-Danish collaboration was involved. The network has a node for each topic identified in the bibliometric analysis. The connections between topics reveal where those topics appeared on the same paper.

The respective topic tree maps of targeted topics such as wind energy, bioenergy and climate change vary substantially. For wind energy, engineering+ is dominant, with Aalborg University (AAU) leading, followed by the Technical University of Denmark (DTU). For bioenergy, waste management, biogas and biomass (within applied social and earth sciences) are dominant, with DTU leading followed by Aarhus University and the University of Copenhagen. For climate change, applied social and earth sciences, in particular environmental resource management and natural resource economics, are dominant, with Aarhus University leading followed by the Chinese Academy of Sciences.

In conclusion, the bibliometric analysis of Sino-Danish cooperation demonstrates that it accelerated from 2005 and has since experienced exponential growth. However, it is challenging to verify the impacts of multiple and simultaneous interventions and to attribute specific

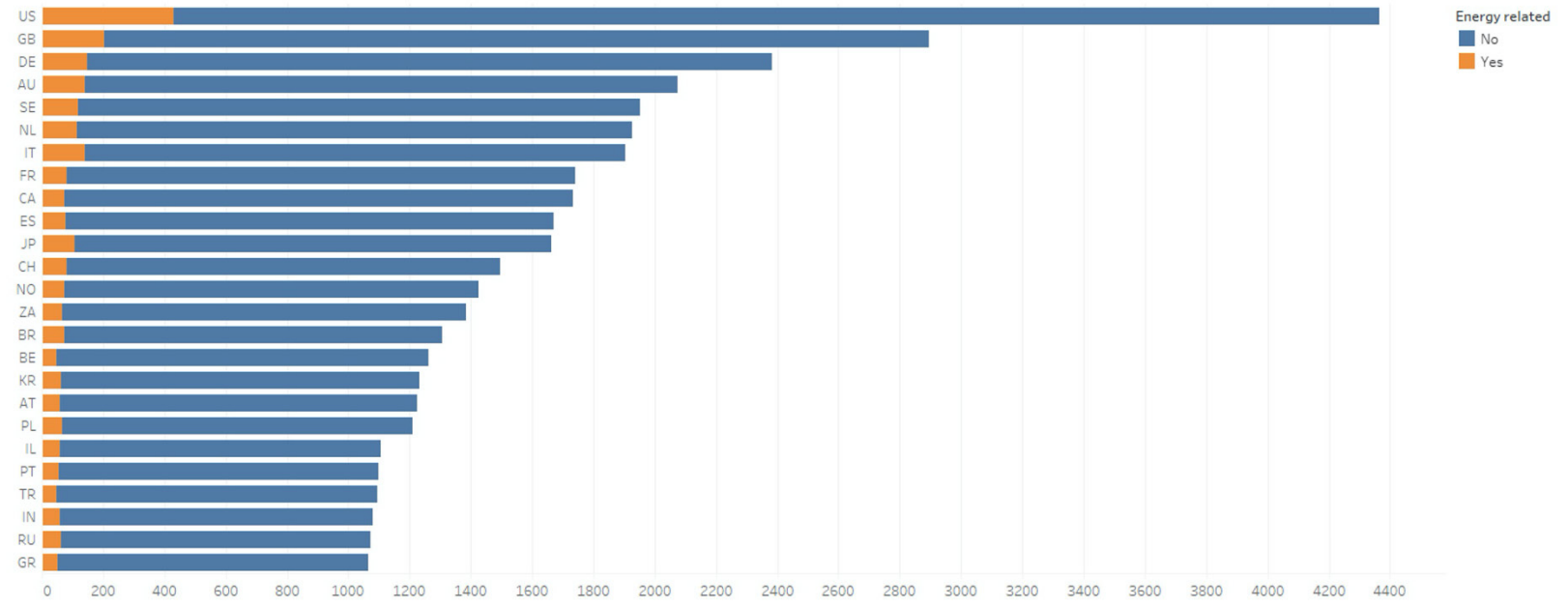

Figure 4 Total co-publication records as per third country partners involved in Sino-Danish RED collaboration 

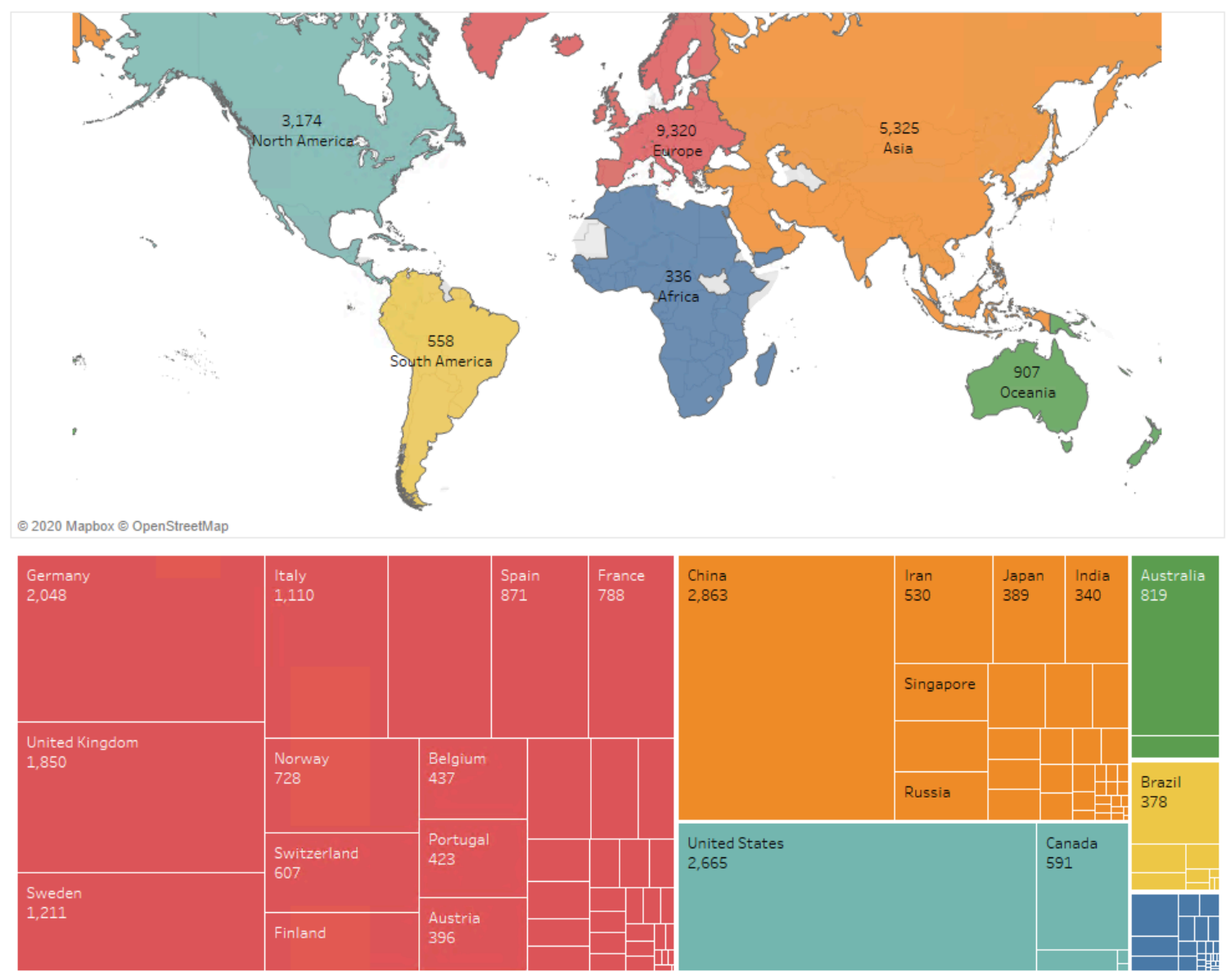

Figure 5 Total global records of scientific co-publication within technical sciences

outputs to collaboration. Researchers and institutions are involved in many international partnerships and receive funding from multiple sources, often for the same project. This growth has been aided by governmental support mechanisms and facilitating frameworks on both sides - unilateral, bilateral, and also multilateral in terms of the EU, the International Energy Agency (IEA), etc. The longer-term impacts of strategic partnerships and targeted support mechanisms are not yet evident. Due to its scale ${ }^{2}$, China is the leading funding source of Sino-Danish cooperation. This is also true of the energy area, even though Danish research councils and private foundations have also supported Sino-Danish research. It is also significant to note that cooperation encompasses global scientific communities in the USA, the United Kingdom and Germany. Due to the role of engineering in energy technologies and systems, topic areas are dominated by engineering+ disciplines, though generic topics such as materials also play a central role in cooperation. Social science is mainly limited to disciplines such as socio-economic transformation, sociology, political science, business management and economics, and social

2 The Chinese Mid to Long-Term S\&T Development Plan (2006-2020) set a goal of doubling national R\&D investment to $2.5 \%$ of GDP by 2020 and China is on track to achieve this goal (Basu et al. 2018). development. Technical and social sciences are increasingly important in the energy transition as it necessitates a more complex systemic and user-centric approach driven by multiple disciplines and co-creation across themes and space. However, co-publication mapping does not corroborate this need. Sino-Danish cooperation would benefit from incentives and mechanisms that support such an approach, with an emphasis on technology for people and not the other way round.

\section{Conclusion - the reciprocity of cooperation}

Given the urgency of the energy and climate challenge, innovation and large-scale adoption of clean energy technologies are the key actions to hasten the energy revolution. International cooperation is particularly critical if this transformation is to be dramatically accelerated. Both China and Denmark have set ambitious goals to transform their domestic energy systems and both countries collaborate internationally to gain mutual benefits such as access to knowledge, people and resources and access to promising markets and positioning on the global scene. International cooperation increases both the scope and the scale of research and is therefore seen as more effective and efficient in developing solutions to pressing challenges and problems related to the energy system. International cooperation is difficult and sometimes associated with 


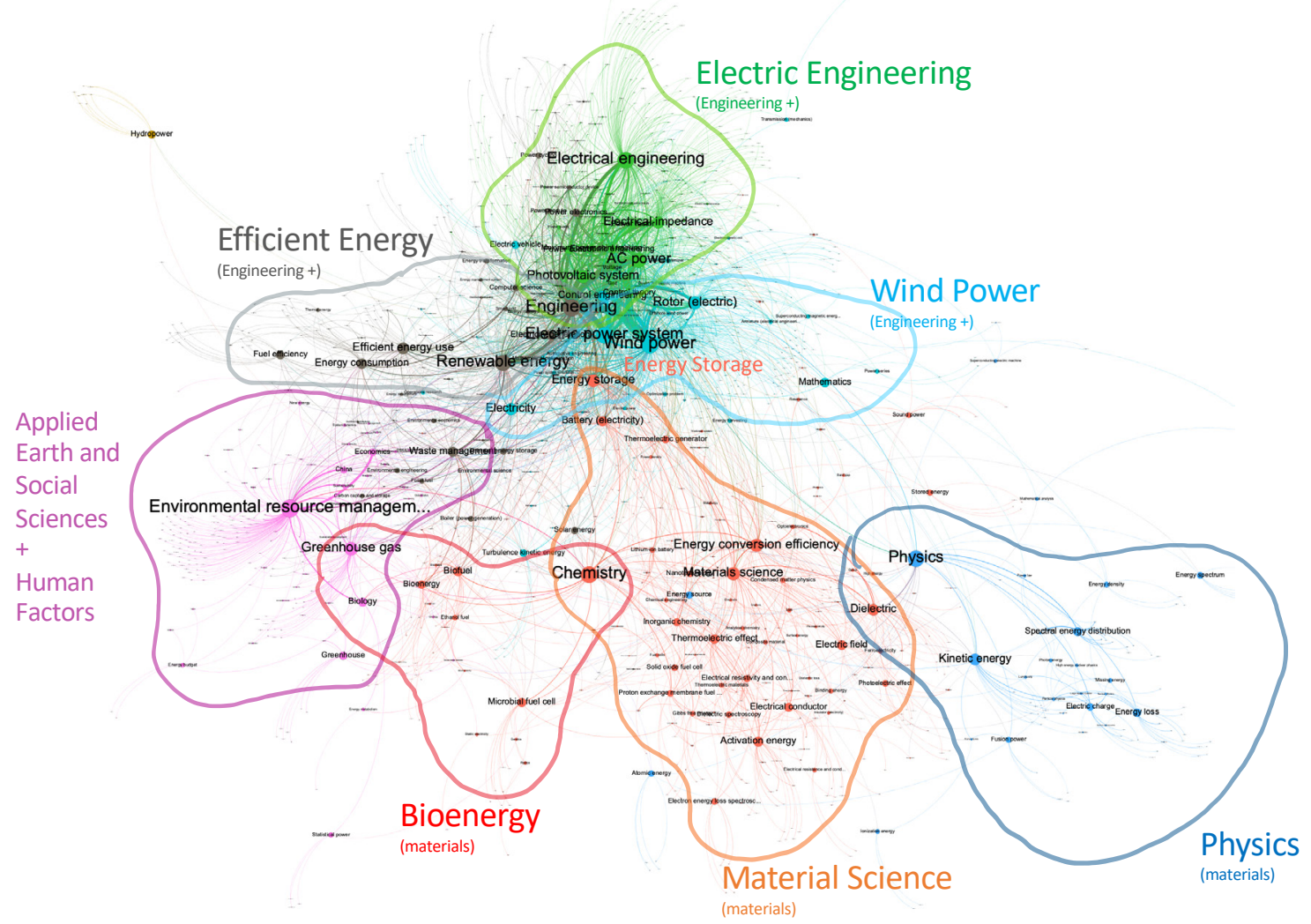

Figure 6 Annotated network view of the connections between energy transition topics. Each node is a topic, the connections between nodes show where topics were used in the same publication. The colours show lower level clusters, specialized technological areas.

transaction costs related, for example, to robust IPR arrangements and investments into the building of networks and markets. As collaboration evolves and the model for undertaking Sino-Danish projects is finetuned, a potential pathway is set out for higher levels of engagement in other areas and in addressing other global challenges. Covid-19 is a good example of such a challenge.

For a small, open economy such as Denmark, international cooperation with a large country such as China is decisive for the further development of scientific disciplines and knowledge and the economic competitiveness of the energy industry in global markets. China offers a scale of markets, resources and expertise that cannot be matched by a small country. China is also leading in key areas for the energy transition, such as digitisation, artificial intelligence and batteries. However, as a member of the EU, Denmark constitutes an entry point for China into the EU and its markets. Denmark is a leader in terms of transforming the energy system, with the highest global share of renewables and a competitive science and engineering wind technology sector (ATV 2020). This has been driven by a combination of ambitious and protective policies, good framework conditions and strong research communities within renewable technologies.
In times of a global health and climate crisis, international cooperation is vital to accelerate the energy transition. The IEA has identified key principles to compress the innovation cycle and deliver on net-zero emission targets (IEA 2020) and most of them are shared by Sino-Danish energy cooperation.

1. Energy sectors have identified and prioritized cooperation areas and have adapted to local requirements and conditions.

2. Both China and Denmark have doubled public energy R\&D over the last 5 years and enabled marRet-led innovation.

3. Cooperation addresses all links in the knowledge value chain from basic research to demonstrations and market initiation.

4. Both countries have enabled knowledge infrastructures such as access to public and private finance and networks.

5. Both countries engage in the broader international community to exchange and create new knowledge, preventing knowledge gaps and creating cross-border synergies. 


\section{References}

ATV. 2020. Verdens førende tech-regioner. Danmarks styrkepositioner i et globalt perspektiv. En rapport fra ATVs Sceince and Engineering projekt, August 2020. https://atv. dk/udgivelser-viden/verdens-foerende-tech-regioner-danmarks-styrkepositioner-globalt-perspektiv

Archibugi, D., Howells, J., \& Michie, J. 1999. 'Innovation systems in a global economy'. Technology Analysis \& Strategic Management, 11(4), 527-539.

Anadon, L., Bunn, M., Narayanamurti, V. (eds.), 2014. Transforming U.S. Energy Innovation. Cambridge: Cambridge University Press.

Barnard, H., and Chaminade, C. 2017. 'Openness of innovation systems through global innovation networks: a comparative analysis of firms in developed and emerging economies'. International Journal of Technological Learning, Innovation and Development, 9(3), 269-292.

Boekholt, P., Edler, J., Cunningham, P. and Flanagan, K. 2009. Drivers of International collaboration in research. Final report April 2009. EU Commission, available at: https://ec.europa.eu/research/evaluations/pdf/archive/ other_reports_studies_and_documents/drivers_of_international_cooperation_in_research.pdf

D'Hoodge, I., Montulet, A., de Wolf, M. and Pieke, F.N. 2018. Assessing Europe-China Collaboration in Higher Education and Research. Leiden Asia Centre. https://leidenasiacentre. nl/wp-content/uploads/2018/11/LeidenAsiaCentre-Report-Assessing-Europe-China-Collaboration-in-Higher-Education-and-Research.pdf

Edler, J. 2012. 'Toward Variable Funding for International Science'. Science, 338(6105): pp. 331-332. DOI: 10.1126/science.1221970.

Ernst, D. 2002. 'Global production networks and the changing geography of innovation systems. Implications for developing countries'. Economics of innovation and new technology, 11(6): pp. 497-523.

EU Commission, 2012. Enhancing and focusing EU international cooperation in research and innovation: A strategic approach. COM (2012) 497 final. https://ec.europa.eu/ research/iscp/pdf/policy/com_2012_497_communication_from_commission_to_inst_en.pdf

Fu, X. 2015. China's path to innovation. Cambridge: Cambridge University Press.

Fu, X., and Mu, R. 2014. 'Enhancing China's innovation performance: The policy choices'. China \& World Economy, 22(2): pp. 42-60.
Geels, F. W. and Schot, J. 2007. 'Typology of sociotechnical transition pathways'. Research policy, 36(3): pp. 399-417.

Georghiou, L. 1998. 'Global cooperation in research'. Research Policy, 27: pp. 611-626.

Gluckman, P. D., Turekian, V. C., Grimes, R. W. and Kishi, T. 2017.' Science Diplomacy: A Pragmatic Perspective from the Inside'. Science \& Diplomacy, 6(4).

Gray, J. E., Wonder, E. F., Kratzer and Myron B. 1985. 'International Energy Research and Development Cooperation'. Ann. Rev. Energy, 10: pp. 589-611.

Grin, J., Rotmans, J., and Schot, J. 2010. Transitions to sustainable development: new directions in the study of long term transformative change. London: Routledge.

Gu, S., Schwaag Serger, S. and Lundvall, B. A. 2016. 'China's innovation system: ten years on'. Innovation, 18(4): pp. 441-448.

Haakonsson, S., Kirkegaard, J. K, and Lema, R. 2020. 'The decomposition of innovation in Europe and China's catchup in wind power technology: the role of KIBS'. European Planning Studies, 28(11): pp. 2174-2192.

Haakonsson, S. J., and Slepniov, D., 2018. 'Technology transmission across national innovation systems: The role of Danish suppliers in upgrading the wind energy industry in China'. The European Journal of Development Research, 30(3): pp. 462-480.

IEA, 2020. Energy Technology Perspectives. Special Report on Clean Energy Innovation. Paris. https://www.iea.org/ reports/clean-energy-innovation

IRENA, 2020. Perspectives for the energy transition: Investment Needs for a Low-Carbon Energy System. International Renewable Energy Agency.

Knudsen, M.P., Christensen, J.L. and Christensen, P. 2018. 'RIO Report for Denmark', JRC Science for Policy Report, EU Commission, https://rio.jrc.ec.europa.eu/country-analysis/ Denmark/country-report

Kuemmerle, W. 1999. The drivers of foreign direct investment into research and development: an empirical investigation. Journal of international business studies, 30(1), 1-24.

Lema, R., Fu, X. and Rabellotti, R. 2020. 'Green Windows of Opportunity: Latecomer Development in the Age of Transformation towards Sustainability', Industrial and Corporate Change, 29:5. DOI: 10.1093/icc/dtaaO44 
Mazzucato, M. 2015. 'The green entrepreneurial state'. The politics of green transformations, 134-152.

Mitchell C. 2010. 'Forging European Responses to the Challenge of Climate Change and Energy Resource Supply'. In Prange-Gstöhl, H. (Ed.) International Science and Technology Cooperation in a Globalized World: The External Dimension of the European Research Area. Edward Elgar Publishers.
Parraguez, P. 2020. Mapping Collaborative Sino-Danish RED on Energy Transition. A data driven exploration of research outputs from the 80 s to 2020. Available at: https:// dataverz.gitbook.io/dataverz-outputs/sdc/sdc-energy-transition-r-and-d

World Economic Forum (WEF). 2020. Insight Report: Fostering Effective Energy Transition 2020. World Economic Forum, Geneva.

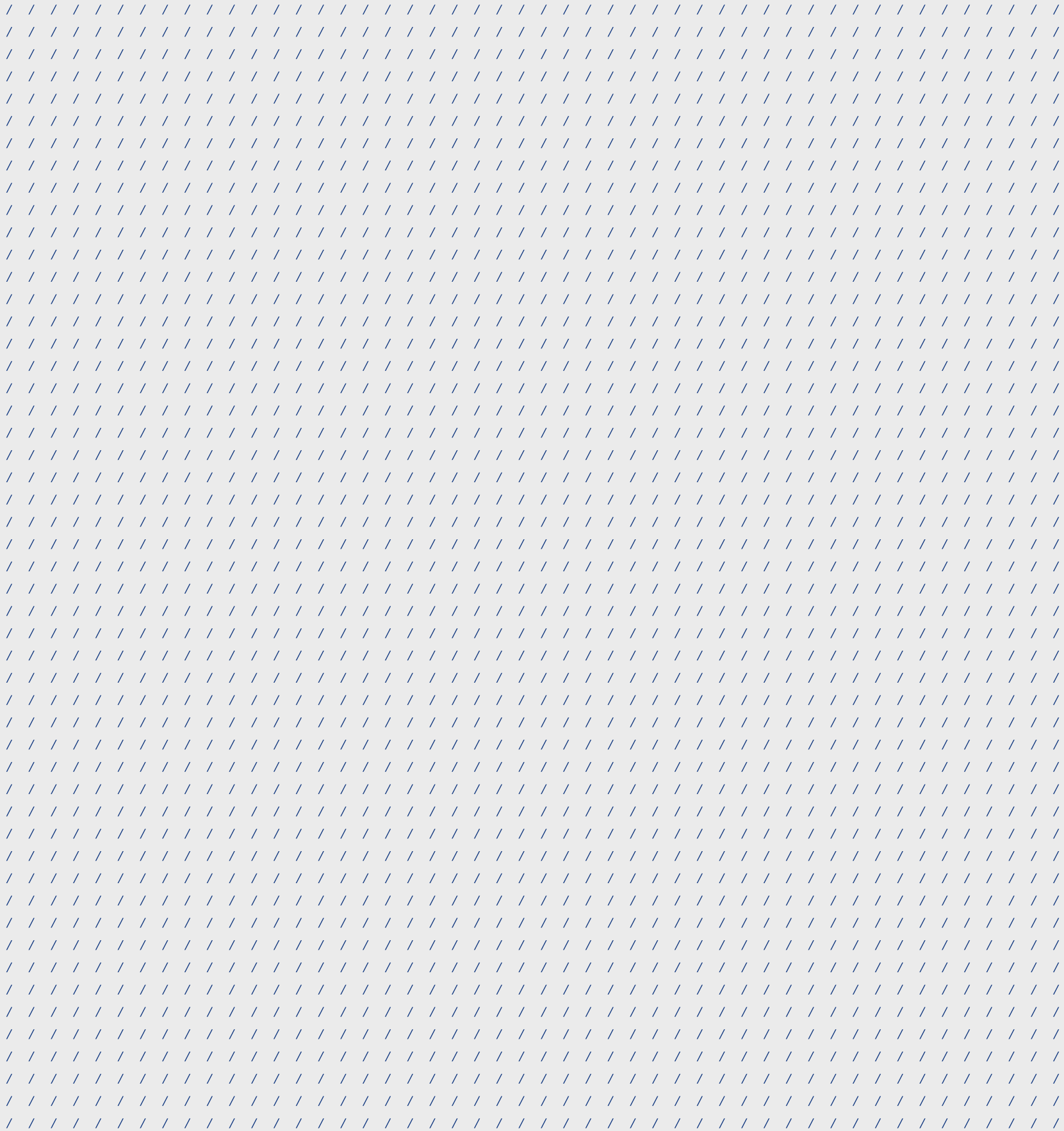

